\title{
Religião e Espiritualidade de Idosos Internados em uma Enfermaria Geriátrica ${ }^{1}$
}

\author{
Flávia Meneses Duarte ${ }^{2}$ \\ Hospital do Servidor Público Estadual - SP \\ Kátia da Silva Wanderley \\ Faculdades Metropolitanas Unidas - FMU \\ Hospital do Servidor Público Estadual de SP
}

\begin{abstract}
RESUMO - Esta pesquisa avaliou a influência da religião e espiritualidade no enfrentamento da hospitalização em pacientes idosos. A amostra foi composta por 30 idosos hospitalizados numa enfermaria geriátrica. Os instrumentos utilizados foram um questionário sociodemográfico e a Escala de Religiosidade DUREL - Duke Religious Index. Religião e espiritualidade são recursos relevantes aos quais idosos recorrem no enfrentamento da hospitalização. Reconhecer o bem-estar que estes aspectos proporcionam aos idosos é prestar atendimento humanizado. Sugere-se o desenvolvimento de mais pesquisas e instrumentos de avaliação acerca do tema, bem como a inclusão de disciplinas que abordam religião e espiritualidade na formação dos profissionais de saúde, dada a importância que a população idosa atribui às suas crenças religiosas e espirituais em momentos de dificuldades.
\end{abstract}

Palavras-chave: religião; espiritualidade; idosos; hospitalização.

\section{Religion and Spirituality of Elderly Living in a Geriatrics Ward}

\begin{abstract}
This study evaluated the influence of religion and spirituality on the way in which elderly patients cope with their hospitalization. A total of 30 elderly living in a geriatrics ward participated in the study. The instruments used were: a socio-demographic questionnaire and the DUREL Religious Scale (Duke Religious Index). Results indicate that the elderly attach much importance to their spiritual and religious beliefs to cope with their hospitalization. Recognizing the well-being that these aspects provide for the elderly is to provide humanized care. In order to do that, the development of further research and evaluation tools on the theme is suggested, as well as the inclusion of disciplines of religion and spirituality in the training of health professionals.
\end{abstract}

Key words: religion, spirituality, aged, hospitalization.

O envelhecimento populacional é um fenômeno que teve início na década de 1960. Nas primeiras quatro décadas do século passado, os idosos correspondiam a 2,5\% da população (Chaimowicz, 1997). A combinação da queda nas taxas de mortalidade infantil com elevadas taxas de fecundidade, permitiu que pessoas nascidas entre 1940 e 1960 completassem 65 anos em 2005, dando início à fase rápida do envelhecimento populacional. “A proporção de idosos com mais de 65 anos saltará dos atuais $9 \%$ para $18 \%$ em 2050 , quando somarão 38 milhões" (Chaimowicz, 2006, p. 106).

$\mathrm{O}$ aumento da expectativa de vida entre idosos e estudos sobre o bem-estar na velhice vêm crescendo e apontam para a importância da religiosidade e da espiritualidade como recurso de enfrentamento diante de eventos estressantes, temas até então negligenciados pela ciência e gerontologia (Sommerhalder \& Goldstein, 2006).

1 Não houve financiamento; qualquer tipo de despesa foi custeado pela primeira autora, sem ônus para a instituição. O presente trabalho foi desenvolvido como requisito parcial para obtenção do título de aprimoranda em atendimento interdisciplinar em geriatria e gerontologia do Hospital do Servidor Público Estadual - SP, sob supervisão e orientação da segunda autora.

2 Endereço para correspondência: Hospital do Servidor Público Estadual (HSPE) - Ambulatório de Geriatria e Crônicos. Rua Pedro de Toledo, 1900, Vila Clementino, São Paulo, SP, CEP: 04029-000. E-mail: flaviameneses@yahoo.com.br
Religião e espiritualidade são fenômenos relevantes na vida dos brasileiros - 92,51\% da população declarou ser adepto de uma religião no censo demográfico de 2000 (Santana, 2006). Especialmente na velhice, religião e espiritualidade ocupam lugar de destaque, já que o envelhecimento traz consigo questões existenciais que a religião tenta responder (Sommerhalder \& Goldstein, 2006). Além disso, os idosos não enfrentaram o pluralismo religioso dos dias atuais, pelo qual os mais jovens são influenciados. A religião ainda é identificada como fonte de significação na vida. A tradição e a experiência religiosa levam os idosos a crer (Santana, 2006).

Com o crescente interesse da literatura científica em explorar as implicações da religião e da espiritualidade em contextos de saúde física e mental, observou-se que os achados não são unívocos. Contudo, evidências demonstram que religiosidade e espiritualidade podem contribuir para o bem-estar pessoal, além de reduzir os níveis de depressão, angústia, morbidade e mortalidade (Duarte, Lebrão \& Laurenti 2008).

\section{Religião e espiritualidade como enfrentamento em contextos de saúde-doença}

Religião e espiritualidade são termos que, devido a falta de consenso na literatura científica em relação a conceituação, dificulta pesquisas acerca do tema. Assim, este estudo baseia-se nas definições a seguir. 
Religião é um sistema organizado de crenças, práticas, rituais e símbolos destinados a facilitar a proximidade do indivíduo com o sagrado ou o transcendente (Koenig, McCullough \& Larson, 2001).

A espiritualidade tem a ver com reflexão, uma busca pessoal sobre o significado da vida e a relação com o sagrado ou o transcendente. A espiritualidade pode ou não estar vinculada a uma religião (Koenig e cols., 2001). As pessoas podem ter crenças individuais sem se voltar a um deus ou a crenças e atividades específicas de uma religião (Sommerhalder \& Goldstein, 2006).

Para Allport e Ross (1967), o indivíduo pode experienciar sua religião de duas maneiras: extrínseca ou intrínseca. A maneira extrínseca refere-se a utilizar a religião como meio de obter benefícios. Neste caso, a religião ocupa um lugar superficial em sua vida; suas crenças religiosas são herdadas, não houve reflexão sobre a escolha da filosofia religiosa (Drucker, 2005). Vivenciar a religião de maneira intrínseca significa colocar suas crenças religiosas em primeiro lugar; é viver de acordo com seus preceitos, numa atitude de comprometimento e busca de sentido da vida (Allport \& Ross, 1967).

Os idosos estão mais vulneráveis a sofrerem perdas. A quantidade de anos vividos lhe permitiu experenciar diversos fatos e, especialmente na velhice, a soma de perdas pode acarretar conseqüências negativas em sua saúde. A perda financeira, da situação econômica decorrente da aposentadoria; a perda da beleza, do vigor da juventude; a perda de um corpo saudável para dar lugar à convivência com doenças crônicas; a perda de independência e/ou autonomia; a perda de familiares, amigos e, finalmente, a proximidade da perda da própria vida. A religião e a espiritualidade podem auxiliar no enfrentamento destes eventos, considerados frequentemente como estressores.

A hospitalização também representa um evento estressor. A doença, os sintomas físicos, os procedimentos invasivos, a dependência, a quebra de rotina e de papéis sociais, a distância dos familiares, a gravidade do estado de saúde, o medo do desconhecido e fantasias sobre a morte são condições frequentemente vivenciadas.

De acordo com Aldwin (2000), grande parte da literatura sobre enfrentamento dedica-se a compreender as estratégias utilizadas para lidar com doenças e procedimentos médicos, especialmente, doenças cardíacas, diabetes, artrite reumatóide, câncer e AIDS.

Pargament et al. (1988) identificam três estilos de enfrentamento de problemas relacionados com a responsabilidade da pessoa e religião. São eles: autodirigido, delegante e colaborativo.

O estilo autodirigido diz respeito ao indivíduo que assume a responsabilidade sobre a resolução dos seus problemas, não espera em Deus. Já o estilo delegante, refere-se à espera em Deus para a resolução dos seus problemas, se eximindo de qualquer responsabilidade. No estilo colaborativo, indivíduo e Deus participam da resolução de problemas, cada um faz sua parte. É importante lembrar que, uma mesma pessoa pode utilizar de estilos diferentes na resolução de problemas. Isto vai depender do quanto se acha competente diante da situação (Faria \& Seidl, 2005).

Koenig, George e Titus (2004) entrevistaram 838 pacientes hospitalizados com idade superior a 50 anos, com o objetivo de avaliar os efeitos da religião e espiritualidade e sua relação com suporte social, saúde psicológica e física. Os resultados demonstraram que práticas religiosas e espiritualidade são prevalentes em idosos hospitalizados e estão associadas a maior suporte social, melhor saúde psicológica e, em certa medida, melhor saúde física. Suporte social é um aspecto diretamente ligado ao bem-estar e apareceu com freqüência na amostra, especialmente nos pacientes com idade superior a 75 anos. Além disso, sintomas depressivos foram menos freqüentes nos mais religiosos; práticas religiosas privadas, tais como oração e leitura bíblica podem conduzir a um melhor funcionamento cognitivo, ou talvez mais provável, um melhor funcionamento cognitivo pode facilitar tais atividades, dada a natureza altamente cognitiva das mesmas. A relação com saúde física foi menor quando comparada aos fatores psicossociais, o que era esperado pelos pesquisadores, pois dada a gravidade da doença, as comorbidades e incapacidade, dificulta o acesso do indivíduo a uma igreja ou templo religioso, aumentando as práticas religiosas privadas.

\section{Religião e espiritualidade na atuação do psicólogo hospitalar}

Religião e espiritualidade são recursos utilizados com freqüência por idosos diante de diversos problemas, especialmente quando se trata de doenças. No trabalho realizado na enfermaria geriátrica do Hospital do Servidor Público Estadual de São Paulo é comum ouvir frases como "se Deus quiser vou melhorar", "estou me sentindo melhor, graças a Deus", "é preciso ter fé em Deus para melhorar". Tais frases apontam para a relação da religião ou espiritualidade com otimismo, esperança de melhora, na busca de força num ser superior que possa auxiliar. Esta fé ajuda a enfrentar procedimentos invasivos, a alimentar-se mesmo quando não há apetite algum, como se a crença fosse que Deus já vai fazer sua parte, então, cabe ao paciente cooperar e fazer a dele. Este tipo de pensamento auxilia o trabalho do psicólogo, pois este profissional depende do querer, da aceitação do paciente em ser atendido. A adesão ao tratamento psicológico traz consigo o desejo de sentir-se melhor.

Aldwin (2000) cita sete funções adaptativas principais no enfrentamento de doenças: lidar com conseqüências fisiológicas de doenças, como dor, sintomas e incapacidade; lidar com o tratamento e o ambiente hospitalar; desenvolver e manter boas relações com a equipe de saúde; manter o equilíbrio emocional; manter um senso de self, incluindo competência e controle; manter boas relações com família e amigos e preparação para futuras exigências.

Uma das intervenções do psicólogo na enfermaria geriátrica do Hospital do Servidor Público Estadual de São Paulo é justamente auxiliar o paciente a desenvolver tais funções adaptativas, para que o período de hospitalização seja o menos desconfortável e aversivo possível, na intenção de propiciar bem-estar psicológico, emocional e espiritual durante a internação. Ao atender os pacientes nos leitos, observa-se se há demanda para atendimento religioso, por meio da relevância que o paciente atribui a religião, principalmente se associado com sentimentos de desesperança 
em relação ao tratamento. Como este hospital dispõe de serviço de capelania, caso o paciente demonstre o desejo de colocar em prática suas crenças religiosas, é informado quanto a disponibilidade do serviço, deixando-o à vontade para escolher se quer ou não o atendimento. A experiência na enfermaria de geriatria e crônicos tem demonstrado que os pacientes aceitam de bom grado o atendimento religioso e relatam sentirem-se melhor após tal assistência. Com ética e respeito pelos valores religiosos e espirituais dos pacientes, o psicólogo pode encontrar na religião e espiritualidade ferramentas úteis que podem auxiliar no atendimento a idosos internados, que encontram na fé otimismo, esperança e motivação para implicar-se e envolver-se com o tratamento, aspectos de extrema relevância para sua recuperação.

Quando questões religiosas e espirituais estão envolvidas no atendimento psicológico, é necessário considerar alguns pontos. O psicólogo deve acima de tudo prezar pela ética e respeito; jamais interferir ou julgar qualquer tipo de crença ou opinião do paciente. Por meio da formação de uma relação empática, buscar compreender o significado e a importância que cada paciente atribui às suas crenças religiosas. Faria e Seidl (2005) atentam para a necessidade de identificar no enfrentamento religioso as potencialidades de ajuda, assim como de prejuízo.

Por prejuízo, aqui entende-se qualquer conduta que, por influência religiosa, venha gerar malefícios à saúde do paciente. Mais comum ao estilo delegante, comportamentos como negligenciar sintomas, descuido com a saúde e não-adesão a práticas preventivas, podem decorrer de um positivismo exagerado, baseado na crença em que o Pai protegerá de qualquer mal, o que facilita a instalação de doenças e retarda a procura por tratamento médico. Assim, a procura por ajuda especializada pode ocorrer num momento em que, devido ao agravo da doença, pouco possa se fazer pelo paciente. Além disso, indisciplina às recomendações médicas, não-adesão ao tratamento proposto e crenças em que a doença é vista como punição, também são consideradas prejudiciais no que se refere a enfretamento religioso.

A Associação Psiquiátrica Americana faz algumas recomendações para psicoterapeutas ao abordarem temas como espiritualidade e religiosidade, entre elas, investigar a importância da religião e espiritualidade no sistema de crenças do paciente e se as mesmas são relevantes a ponto de serem abordadas no atendimento clínico. Além disso, ressalta a importância do psicoterapeuta treinar intervenções apropriadas a assuntos religiosos e espirituais e de manter-se atualizado a respeito das questões éticas que tais temas requerem na prática clínica (Peres, Simão \& Nasello, 2007).

\section{Método}

\section{Participantes}

Trata-se de um estudo transversal. A amostra foi composta por 30 pacientes idosos, com idade igual ou acima de 65 anos, internados na enfermaria geriátrica do Hospital do Servidor Público Estadual de São Paulo. Foram selecionados para este estudo pacientes orientados, lúcidos e sem qualquer déficit cognitivo ou síndrome demencial - mediante dados de prontuário médico.

Dos 30 idosos participantes da pesquisa, nove eram do sexo masculino (30\%) e 21 do sexo feminino (70\%). Apesar de a enfermaria geriátrica admitir pacientes acima de 65 anos, $73 \%$ dos pacientes estavam na faixa etária entre 81 e 95 anos; a média de idade ficou em torno dos 85 anos. Quanto ao nível de escolaridade, a média de anos de estudo foi de 4,03 anos; $37 \%$ possuíam quatro anos de escolaridade e apenas $10 \%$ da população concluiu o segundo grau. Em relação ao estado civil, $57 \%$ são viúvos, $27 \%$ casados, $13 \%$ solteiros e $3 \%$ separados. Pacientes que vivem só são $23 \%$ da amostra, enquanto $77 \%$ vivem acompanhados. São naturais do interior do estado de São Paulo 53\% dos participantes, 23\% de São Paulo capital, $3 \%$ da Grande São Paulo e $20 \%$ de outros estados. Entre os motivos pelo qual foram internados, $40 \%$ se tratavam de doenças do aparelho respiratório (dispnéia, pneumonia, doença pulmonar obstrutiva crônica - DPOC entre outras), $20 \%$ doenças do aparelho circulatório, $13 \%$ por infecção do trato urinário, $3 \%$ neoplasias e outros sintomas somam $23 \%$ das internações. A maioria $(80 \%)$ reside na capital paulistana. Quanto à religião, 73\% denominam-se católicos, $17 \%$ evangélicos, $7 \%$ espíritas e 3\% outras religiões. É interessante frisar aqui que $100 \%$ dos pacientes evangélicos são do sexo feminino.

\section{Instrumentos}

Foi aplicado um formulário sócio-demográfico desenvolvido especificamente para o estudo com o objetivo de obter informações quanto ao gênero, idade, estado civil, escolaridade, religião declarada e motivo da internação do paciente na enfermaria. $\mathrm{O}$ instrumento escolhido para avaliar o índice de religiosidade foi a Escala de Religiosidade DUREL (Duke Religious Index). Com o crescente interesse da ciência em realizar pesquisas acerca do tema em contextos de saúde-doença, constatou-se uma limitação ao desenvolvimento de mais pesquisas em países de língua portuguesa devido à carência de instrumentos que pudessem fornecer dados relevantes e, ao mesmo tempo, que fossem curtos e simples. Assim, a escala que foi desenvolvida com a população americana, foi traduzida para o português e revisada por pesquisadores brasileiros. Posteriormente, retrotraduziram-na para o inglês e foi enviada para seu autor, que avaliou e aprovou a versão final em português. Esta versão ainda não foi validada para a população brasileira. Porém, como assinalam os autores "o fato de ambos os países serem majoritariamente cristãos e de a DUREL apresentar itens mais genéricos, provavelmente aplicáveis à maioria das religiões de nosso meio, sugere que essa versão em português possa ser bem aplicável em nossa realidade" (Moreira-Almeida, Peres, Aloe, Lotufo-Neto \& Koenig, 2008, p. 31).

A DUREL é uma escala que compreende três das dimensões de religiosidade que mais se relacionam com saúde: organizacional (RO), não-organizacional (RNO) e religiosidade intrínseca (RI). É composta por cinco itens e na análise dos resultados, as pontuações nas três dimensões (RO, RNO e RI) são analisadas isoladamente. Os escores 
dessas três dimensões não são somados em um escore total (Moreira-Almeida e cols., 2008).

Religiosidade Organizacional $(\mathrm{RO})$ refere-se à participação e freqüência em igrejas, templos ou encontros religiosos, ou seja, a Religiosidade Organizacional está relacionada a um componente social. Religiosidade Não-Organizacional (RNO), diz respeito a atividades religiosas que podem ser realizadas a partir da privacidade do lar como orações, leituras e programas de TV e/ou rádio e que independem da interação com outras pessoas (Koenig e cols., 2001). Finalmente, a Religiosidade Intrínseca (RI) avalia o quanto a religião pode motivar ou influenciar nos comportamentos, decisões e, de forma geral, na vida do sujeito (Koenig e cols., 2004). Trata-se de uma dimensão subjetiva, do quanto e como o indivíduo percebe a importância da religião em sua vida (Koenig e cols., 2001).

\section{Procedimentos}

Após o paciente ser admitido na enfermaria de geriatria e crônicos, é procedimento de rotina passar por uma entrevista de triagem psicológica, com o objetivo de verificar se o paciente apresenta demanda para atendimento. Por meio desta triagem, colhem-se dados sócio-demográficos, informações sobre dinâmica familiar, história de vida do sujeito, histórico de tratamentos de saúde entre outros.

$\mathrm{Na}$ triagem os participantes e seus acompanhantes foram orientados quanto aos objetivos deste estudo, dos aspectos éticos e da participação voluntária na pesquisa. Após autorização do paciente, o mesmo assinou o Termo de Consentimento Livre e Esclarecido (TCLE). No caso do paciente estar impossibilitado fisicamente de assinar ou ler o termo de consentimento, bem como o instrumento, foi solicitado ao acompanhante que presenciasse a aplicação dos instrumentos e que assinasse como testemunha, mediante consentimento do paciente. A coleta de dados ocorreu no leito.

\section{Resultados}

Quando questionados em relação a freqüência com que vão a uma igreja, templo ou outro encontro religioso, 20\% dos pacientes responderam que freqüentam uma ou mais vezes por semana; $13 \%$ duas a três vezes por mês; $20 \%$ algumas vezes por ano; $30 \%$ uma vez por ano ou menos e $17 \%$ relataram nunca freqüentar. Neste item, considerou-se "nunca" pacientes que não freqüentam qualquer encontro religioso pelo menos há mais de dois anos.

Em relação a freqüência com que dedicam seu tempo a atividades religiosas individuais, como preces, rezas, meditações, leitura bíblica ou outros textos religiosos, $60 \%$ relataram que realizam tais práticas mais do que uma vez ao dia; $30 \%$ uma vez ao dia e $10 \%$ duas ou mais vezes por semana.

Para avaliar a religiosidade intrínseca, são colocadas três frases a respeito de crenças ou experiências religiosas e pede-se que responda o quanto cada frase se aplica ao indivíduo. $\mathrm{Na}$ frase "Em minha vida, eu sinto a presença de Deus (ou do Espírito Santo)", 90\% responderam ser "totalmente verdade" e 10\% "em geral é verdade". A frase seguinte era "As minhas crenças religiosas estão realmente por trás de toda a minha maneira de viver". "Totalmente verdade" foi a opção escolhida por $87 \%$ dos participantes, enquanto "em geral é verdade" se aplicou a 13\% dos mesmos. A última frase "Eu me esforço muito para viver a minha religião em todos os aspectos da vida" 43\% responderam "totalmente verdade", $13 \%$ "em geral é verdade", $3 \%$ "não estou certo", 10\% “em geral não é verdade" e, finalmente, $30 \%$ "não é verdade".

\section{Discussão}

A proporção da denominação religiosa da amostra coincide com os dados do censo de 2000: em ambas, os católicos são maioria, seguido dos evangélicos, espíritas e outras. A média da faixa etária da amostra - 85 anos - reflete o envelhecimento populacional. Os idosos em sua maioria eram octogenários $(83 \%)$.

Em relação a importância que o indivíduo atribui a religião e espiritualidade em sua vida (religiosidade intrínseca), a grande maioria dos pacientes referiram sentir a presença de Deus em suas vidas, bem como as crenças religiosas estão por trás da forma como vivem. Apesar disso, quando questionados em relação à freqüência com que participam de atividades sociais religiosas, como idas a cultos, templos ou encontros religiosos, apenas $20 \%$ dos pacientes freqüentam uma ou mais vezes por semana. A maior parte referiu freqüentar tais encontros uma vez por ano ou menos $(30 \%)$, sendo que $17 \%$ dos pacientes não freqüentam há mais de dois anos. Em contrapartida, com a redução das atividades religiosas sociais, aumenta a prática de atividades religiosas individuais. Pelo menos $90 \%$ da amostra realiza atividades religiosas individuais ao menos uma vez ao dia. Este dado sugere que a importância que a religião ocupa na vida destas pessoas, não pode ser mensurada pelo quanto se freqüenta uma igreja e sim, pelo significado atribuído aos mesmos e as práticas religiosas individuais. Além disso, com o avançar da idade, o idoso se depara com limitações físicas, como dificuldade de locomoção, decorrentes de doenças crônicas, de seqüelas de acidente vascular encefálico, da própria idade entre outros fatores. Soma-se a isto, o medo de quedas, medo de sair sem companhia e passar por qualquer tipo de apuro ou violência.

Baseado em dados do Datasus, no ano de 2005, apesar do maior número de internações hospitalares ocorrer entre adultos, o número aparentemente baixo de internações de idosos oculta elevada taxa, pois são internados com maior freqüência (Chaimowicz, 2006). Frente a esses dados, faz-se relevante reconhecer a importância da religião e espiritualidade na vida de idosos, especialmente em situações de agravos à saúde, visto que tais aspectos são utilizados com freqüência no enfrentamento de eventos estressores.

O objetivo deste estudo foi avaliar de que maneira religião e espiritualidade influenciam no enfrentamento da doença e hospitalização em pacientes idosos. Por meio dos achados deste trabalho foi possível constatar a relevância da religião e espiritualidade como recurso de enfrentamento em idosos hospitalizados numa enfermaria geriátrica, dada a importância que atribuem às práticas religiosas privadas e a freqüência com que recorrem às mesmas. Buscar apoio 
na religião e espiritualidade ajuda a preencher a distância da família, da rotina; presta acolhimento, alento para suportar as vicissitudes impostas pela rotina hospitalar. Num cenário em que a humanização hospitalar vem ganhando forças, atentar para religião e espiritualidade é prestar atendimento humanizado, olhar o paciente não como um corpo que adoece e sim, levar em consideração toda a sua história de vida, hábitos, costumes, cultura e assim evitar a sensação de ser apenas mais um leito ocupado, alguém despersonalizado.

Uma das preocupações da humanização hospitalar é justamente cuidar dos profissionais de saúde para que estes sejam capazes de promover a humanização no serviço. Para tanto, sugere-se que os profissionais de saúde que trabalham com o público idoso estejam familiarizados com o tema e cientes da relevância na vida dos mesmos. Além disso, a inclusão de disciplinas que abordam religião e espiritualidade na formação dos profissionais de saúde pode melhor prepará-los para o manejo de tais assuntos em sua prática profissional, dada a importância que a população de forma geral atribui às suas crenças religiosas e espirituais em momentos de dificuldades. "É no processo de formação que se podem enraizar valores e atitudes de respeito à vida humana, indispensáveis à consolidação e à sustentação de uma nova cultura de atendimento à saúde" (Ministério da Saúde, 2001, p.5).

Por fim, o presente estudo tem o intuito de mostrar à comunidade científica a relevância da religião e espiritualidade como recursos de enfrentamento, servindo de estímulo para o desenvolvimento de mais pesquisas acerca do tema e de uma maior variedade de instrumentos que avaliem os efeitos que religião e espiritualidade têm sobre a população idosa, visto que ainda há pouca atenção por parte da gerontologia em relação ao bem-estar que a religião e espiritualidade proporcionam aos idosos, representa uma importante contribuição para a área.

\section{Referências}

Aldwin, C. M. (2000). Stress, coping and development: An integrative perspective. New York: The Guilford Press.

Allport, G. W., \& Ross, J. M. (1967). Personal religious orientation and prejudice. Journal of Personality and Social Psychology, 5(4), 432-443.

Brasil, Ministério da Saúde, Secretaria de assistência à saúde (2001). Programa nacional de humanização da assistência hospitalar. Ministério da Saúde, secretaria de assistência à saúde, Brasília.

Chaimowicz, F. (1997). A saúde dos idosos brasileiros às vésperas do século XXI: problemas, projeções e alternativas. Revista de Saúde Pública, 31(2), 184-200.
Chaimowicz, F. (2006). Epidemiologia e o envelhecimento no Brasil. Em E. V. Freitas, L. Py, F. A. X. Cançado \& M. L. Gorzoni (Eds.). Tratado de Geriatria e Gerontologia (2 $\left.2^{\mathrm{a}} \mathrm{ed}.\right)$. (pp.106-130). Rio de Janeiro: Guanabara Koogan.

Duarte, Y. A. O., Lebrão, M. L., \& Laurenti, R. (2008). Religiosidade e envelhecimento: uma análise do perfil de idosos do município de São Paulo. Saúde Coletiva, 5(24), 173-177.

Drucker, C. (2005). Religiosidade, crenças e atitudes em idosos deprimidos: em um serviço de saúde mental de São Paulo, Brasil. Dissertação de Mestrado, Universidade Estadual de Campinas, São Paulo, Brasil.

Faria, J. B., \& Seidl, E. M. F. (2005). Religiosidade e enfrentamento em contextos de saúde e doença: uma revisão de literatura. Psicologia: Reflexão e Crítica, 18(3), 381- 389.

Koenig, H. G., George, L. K., \& Titus, P. (2004). Religion, spirituality, and health in medically ill hospitalized older patients. Journal of American Geriatrics Society, 52(4), 54-562.

Koenig, H. G., McCullough, M. E., \& Larson, D. B. (2001). Handbook of religion and health. New York: Oxford University.

Moreira-Almeida, A, Peres, M. F., Aloe, F., Lotufo-Neto, F., \& Koenig, H. G. (2008). Versão em português da Escala de Religiosidade da Duke-DUREL. Revista de Psiquiatria Clínica, 35(1), 31-32.

Pargament, K. I., Kennell, J., Hathaway, W., Grevengoed, N., Newman, J., \& Jones, W. (1988). Religion and the problemsolving process: three styles of coping. Journal for the Scientific Study of Religion, 27, 90-104.

Peres, J. F. P., Simão, M. J. P., \& Nasello, A. G. (2007). Espiritualidade, religiosidade e psicoterapia. Revista de Psiquiatria Clínica, 1, 136-145.

Santana, M. C. (2006). Significados de religiosidade segundo idosos residentes na comunidade: dados do PENSA. Dissertação de Mestrado, Universidade Estadual de Campinas, São Paulo.

Sommerhalder, C., \& Goldstein, L. L. (2006). O papel da espiritualidade e da religiosidade na vida adulta e na velhice. Em E. V. Freitas, L. Py, F. A. X. Cançado \& M. L. Gorzoni (Eds.). Tratado de Geriatria e Gerontologia (2a ed), (pp.13071315). Rio de Janeiro: Guanabara Koogan.

Recebido em 24.04.2009

Primeira decisão editorial em 26.01.2010

Versão final em 24.02.2010

Aceito em 03.01.2011 